Drought analysis in relation to crop production: Anuradhapura district

\author{
M K N Kumari and C M Navaratne \\ Department of Agricultural Engineering, University of Ruhuna, Sri Lanka.
}

In order to identify the risk on drought for crop production in Anuradhapura district, daily rainfall data over 35 years in seven rain gauge stations were analyzed. The selected stations were Anuradhapura, Mahailluppallama, Nochchiyagama, Kalawewa, Elayapaththuwa, Padaviya and Vavuniya.

Among all the stations, both highest mean annual rainfall of $1488.5 \mathrm{~mm}$ and annual dependable rainfall of $1276.6 \mathrm{~mm}$ were recorded in Padaviya. The minimum rainfall values of $1087.6 \mathrm{~mm}$ and $903.1 \mathrm{~mm}$ were noted in Nochchiyagama respectively. $31 \%$ and $69 \%$ of total annual rainfall was received in yala and maha seasons respectively. Number of dry weeks in the district was assessed by Hargreaves' Moisture Availability Index (MAI) method and $10 \mathrm{~mm}$ and $20 \mathrm{~mm}$ weekly rainfall at $75 \%$ probability level for upland and wetland crops respectively.

According to MAI, average number of dry weeks in the district was 25 (out of 26) for yala season and 19 (out of 26) for maha season. The maximum dry period of $100 \%$ was recorded in Nochchiyagama, Elyapaththuwa and Padaviya in yala season. It was $85 \%$ for maha season in Nochchiyagama and Elayapaththuwa. The highest dry run of 42 weeks was recorded in Nochchiyagama, Elayapaththuwa and Padaviya throughout the year. Based on the monthly dependable rainfall $74.5 \%$ of total rainfall is concentrated into last 3 months in the region.

Based on $20 \mathrm{~mm}$ weekly rainfall at $75 \%$ probability, the whole district was completely dry during yala season. Total 100\% dryness was observed in Elayapathtuwa based on $10 \mathrm{~mm}$ and $20 \mathrm{~mm}$ weekly rainfall at $75 \%$ probability for maha season. Average $96 \%$ of dryness was recorded in the district under $10 \mathrm{~mm}$ weekly rainfall at $75 \%$ probability in yala season.

The analysis depicts the risk on drought in the area for crop production. It indicates the irrigation need for the crop production in the district both in yala and maha seasons.

\title{
$\underline{022}$
}

\section{Role of plants in traditional livestock production}

\author{
A N F Perera ${ }^{1}$, A N K Perera ${ }^{2}$ and E R K Perera ${ }^{3}$ \\ Uva Welassa University, Badulla, Sri Lanka \\ University of Wayamba, Sri Lanka \\ 3University of Peradeniya, Sri Lanka
}

Plants have been used from ancient time to sustain local livestock production in various aspects. Historically, traditional veterinary practices were mainly based on the "Hela Vedakama" in which plants played a vital role. Phyto-based traditional veterinary practices dated back to beyond the period of King Ravana. This "phyto-based" system sustained the local livestock production over a period of many ceturies to date and same remedies are presently used extensively and effectively in rural livestock production systems. According to the chronicles and traditional knowledge based information, the cattle can suffer from 16400 and the buffalo from 4448 different ailments. In traditional veterinary practices the most important group diseases are known as "Veppu" and "Adappan". In this category there are more than 4000 different diseases. Majority of these diseases are cured with phyto-based medicinal system. When obtaining plant parts for treatment selection criteria for the plant is very important. Usually "pancha pangu" is used in preparations. Collection of plant aprts are done by auspicious time and by specific persons. According to a extensive study conducted during the last three years, it was revealed, 74\% of the surveyed livestock farmers practice "phyto-based" treatments in livestock medicine. Many plant species are used for different cattle ailments. 38 plant species are used to treat wounds, ulcers, cuts and boils. Some of these medicinal recipes are even recommended 
in local traditional veterinary chronicles which are centuries old. 28 plants species are used to treat ailments of the eye including pathogenic infections to physical damages. 22 plant species have been identified to which has been used to treat respiratory disorders and 18 plant species for the preparation of recipes to treat bone fractures and breakages in cattle and buffalo. 18 plant species were recognized that are used for snake bites and 17 for intestinal worm treatments. In treating throat and mouth diseases, 27 plant species are used and for sprains and swellings 17 species are used. Foot and hoof diseases are one of the major ailments in cattle and buffalo and 16 plant species are used in treating such ailments. For the medical preparations for the ear infections, 15 plant species are used and for treatments for the urinary system, 12 plant species are used. Mastitis is a serious udder problem in lactating cows and 16 plant species are in the medicinal preparations. Reproduction associated problems including dystokia, and abortions. proven treatments are made by using 14 plant species. 15 plant species are used to treat external parasitic diseases. This paper will discuss details of the plant species, their parts used, aspects to consider in obtaining of plant parts and preparation of different recipes.

\title{
$\underline{023}$ \\ Energy saving scoop type rotary tiller blade for deep tillage \\ C P Rupasinghe ${ }^{1}$ and H P W Jayasuriya ${ }^{2}$ \\ 'Department of Agriculture Engineering, University of Ruhuna, Sri Lanka. \\ ${ }^{2}$ Asian Institute of Technology, Bangkok, Thailand
}

The energy consumption for the land preparation is excessive during the primary and secondary tillage operations; because of the high draft force required. Many researchers were reported that the reverse rotational rotary tiller had an advantage for the deep tilling on the power requirement compared to the conventional rotary tiller. The reverse rotational rotary tiller can be used for deep tillage with less energy requirement. Three types of scoop type rotary tiller blades were fabricated by changing design parameters of the horizontal portion of the scoop surface of the blade for reverse rotational in order to minimize the re-tillage during deep tillage achieving low power consumption. Blades with cutting angles $25^{\circ}, 35$ and $55^{\circ}$ were tested with conventional blade ( $45^{\circ}$ cutting angle) at $15.6 \%$ soil moisture conditions.

When compared the maximum power and the torque at maximum power, blade with angle $35^{\circ}$ showed best performance, while others were in the order of conventional type $\left(45^{\circ}\right)>55^{\circ}>25^{\circ}$. In terms of soil tilth, significantly better performances were shown by the blades with angles $35^{\circ}$ and $45^{\circ}$ with reducing bulk density and cone penetration resistance values. Blade with angle $35^{\circ}$ showed highest backward throwing distance as $660 \mathrm{~mm}$. Blade with angle $55^{\circ}$ showed lower backward throwing distance. Blade with angle $35^{\circ}$ performed best with lowest power consumption, higher pulverization and backward throwing ability and can be recommended for reverse rotation in deep tillage.

\section{4}

\section{Sustainability of home gardens in Masemulla forest area in Matara district}

\author{
M K T K Amarasinghe, I R Palihakkara and M de S Liyanage \\ Department of Crop Science, University of Ruhuna, Sri Lanka.
}

Home-gardens are meant to be sustainable land use systems that provide a variety of products and services to the people. This study was undertaken to evaluate the sustainability of home-gardens in Masemulla forest area in Matara district. Ullala, which is a small village closed to Masemulla forest area, was selected for the study. A survey was conducted using a random sample of 40 home-gardens in the area. Average land area ranged from 0.25 to 0.5 acres with an average family size of $2-8$ and almost all the families belonged to the low income group.

Majority of home gardens $(90 \%)$ consisted of three canopy layers-near the ground surface herbaceous layer, followed by an intermediate layer of shrubs and a tree layer at the upper level. Tree density ranged from low to medium with a combination of mixed species arranged in a random way. Canopy coverage was about 15 to $50 \%$ and there were more than $50 \%$ of unutilized land areas. Species diversity in the selected home-gardens was low ranging from 20-25 species and the no of woody taxa 